\title{
ESCARIFICAÇÃO DE UM LATOSSOLO VERMELHO NA PÓS-COLHEITA DE SOQUEIRA DE CANA-DE-AÇÚCAR ${ }^{(1)}$
}

\author{
A. F. PAULINO(2), C. C. MEDINA(3), M. C. B. AZEVEDO(2), \\ K. R. P. SILVEIRA ${ }^{(4)}$, A. A. TREVISAN ${ }^{(4)} \&$ I. M. MURATA ${ }^{(2)}$
}

\begin{abstract}
RESUMO
A escarificação nas entrelinhas da soqueira da cana-de-açúcar, associada à adubação e à gradagem (tríplice cultivo), é adotada como um recurso para amenizar o problema da compactação do solo; entretanto, pouco se sabe de seus efeitos no enraizamento da soqueira. Objetivando estudar os efeitos da escarificação na pós-colheita de cana-de-açúcar nas propriedades físicas de um Latossolo Vermelho, na distribuição de raízes e na produtividade, realizou-se um ensaio na região do Arenito Caiuá, utilizando a terceira soca da variedade R B 72454. Os tratamentos utilizados foram: E 1: escarificação a 0,15 m de profundidade, adubação e gradagem; E 2: escarificação a 0,30 $\mathrm{m}$ de profundidade, adubação e gradagem; GR: adubação e gradagem. Foram avaliados: densidade do solo, porosidade total e distribuição do tamanho de poros; distribuição do sistema radicular; produtividade, perfil hamento, diâmetro e comprimento médios dos colmos. A escarificação nas entrelinhas da soqueira de cana-de-açúcar alterou a densidade do solo, a macro e a microporosidade e, na profundidade de 0,15 m, proporcionou maior comprimento de raízes na camada de 0,25 a 0,50 m, porém não alterou a área e o comprimento totais de raízes para as outras condições estudadas, tampouco a produção da cultura.
\end{abstract}

Termos de indexação: Saccharum sp, manejo do solo, compactação, raízes.

\footnotetext{
(1) Parte da Tese de Mestrado em Agronomia do primeiro autor, Departamento de Agronomia, Universidade Estadual de Londrina - UEL. Recebido para publicação em outubro de 2002 e aprovado em agosto de 2004.

(2) Mestrando em Agronomia, Universidade Estadual de Londrina - UEL. Centro de Ciências Agrárias, Departamento de Agronomia, Caixa Postal 6001, CEP 86.051-990 Londrina (PR). Bolsista CAPES. E-mail: mcbazevedo@hotmail.com

(3) Professora do Departamento de Agronomia, UEL. E-mail: medina@uel.br

(4) Granduando em Agronomia, UEL. Bolsista CNPQ. E-mails: xande.trevisan@bol.com.br; kleytonrps@yahoo.com.br
} 


\title{
SUMMARY: CHISEL PLOWING IN AN OXISOL IN POST HARVEST OF RATOON CANE
}

\begin{abstract}
Chise plowing in-between rows of sugar cane ratoon, associated with fertilizer and harrowing (triple cultivation) is a common practice to reduce soil compaction, but little is known about its effects on ratoon rooting. The purpose of this study was to evaluate the effects of post-harvest chisel pl owing on thephysical properties of an Oxisol, root distribution, and yield. Theexperiment was set up in an Arenito Caiuá Soil and used thethird ratoon of RB72454 sugar cane variety. The treatments were: El: 0.15 m-deep chisel plowing, fertilization, and harrowing; E2: $0.30 \mathrm{~m}$-deep chisel plowing, fertilization, and harrowing; GR: fertilization and harrowing. Thefol lowing parameters wereevaluated: soil bulk density, total porosity, poresizedistribution, root system distribution, yiel d, tiller number, and stalk diameter and length. Chise plowing in-between the ratoon cane rows altered thesoil bulk density and pore size distribution. Soil management down to $0.15 \mathrm{~m}$ depth gave rise to longer roots in a depth of $0.25-0.50 \mathrm{~m}$ but affected neither the total root area and length for the other studied conditions nor the sugar caneyield.
\end{abstract}

Index terms: Saccharum sp, soil management, compaction, roots.

\section{INTRODUÇÃO}

Nos últimos 20 anos, as áreas cultivadas com cana-de-açúcar têm-se expandido consideravel mente no Brasil, sendo este o mai or produtor mundial desta cultura (Orlando Filho et al., 1995). Os solos utilizados vão desde Neossolos Quartzarênicos a Latossolos, sendo estes os mais representativos (Silva \& Ribeiro, 1997).

Os solos originados do Arenito Caiuá são classificados, em sua maior parte, como Latossolos, os quais apresentam propriedades físicas favoráveis à exploração agrícola e baixa fertilidade natural (SEAB/PR, 1994). No entanto, à medida que são utilizados para as atividades agrícolas, ocorrem modificações em suas propriedades físicas originais. $\mathrm{E} m$ virtude dessas alterações nas propriedades do solo, é comum a presença de uma camada compactada na parte superior do seu perfil. Nestas áreas, os valores de densidade do solo são mais elevados, a aeração é prejudicada, bem como a penetração e a prol iferação de raízes (Corsini, 1993; Corsini \& Ferraudo, 1999).

As raízes constituem uma parte da planta de extrema importância, uma vez que por meio delas é que ocorre a extração de água e nutrientes, além de servir, ainda, para fixar a planta no solo (Libardi \& Lier, 1999).

O cultivo da cana-de-açúcar envolve o uso de máquinas agrícolas em todas as etapas, desde o preparo do solo até a colheita. Este tráfego de equipamentos pesados sobre o solo pode levar à compactação no perfil, com conseqüentes efeitos negativos na infiltração da água no solo e no desenvol vimento deraízes (Bastos, 1987). O sistema radicular, por sua vez, pode permanecer ativo por um longo período de tempo depois do corte da planta, deixando de funcionar gradual mente, à medida que um sistema novo se forma, ao crescerem os perfilhos da soqueira (Humbert, 1974).

Desta forma, a compactaçãotem si do considerada um dos principais fatores que afetam a produtividade da cana-de-açúcar (Verma, 1995; Albuquerque \& Reinert, 2001). Para contornar esse problema, é feita uma intervenção no solo num manejo de pós-colheita conhecido como tríplice cultivo, que tem os propósitos de descompactação, adubação química e controle de plantas daninhas. Este manejo visa minimizar o problema da compactação do solo por meio da escarificação nas entrelinhas da cultura. Entretanto, existem divergências quanto à sua realização, visto que se acredita que a escarificação possa causar danos ao sistema radicular ainda ativo, mas senescente, bem como ao que está em formação.

O objetivo deste trabal ho foi avaliar os efeitos da escarificação nas propriedades físicas de um L atossolo Vermel ho, na distribuição das raízes e na produtividade de soqueira de cana-de-açúcar no Norte do Paraná.

\section{MATERIAL E MÉTODOS}

O ensaio foi realizado no período de outubro de 2000 a julho de 2001, em solo classificado como Latossolo Vermel ho distroférrico, localizado na região do Arenito Caiuá, cultivado há mais de 15 anos com cana-de-açúcar pela Cooperativa COCAFÉ, no município de Astorga (PR), situado à latitude de 23 o Sul, longitude de 51 ○ 30 ' Oeste e altitude de $550 \mathrm{~m}$. O clima que caracteriza a região é do tipo subtropical úmi do, segundo a classificação climática feita por Wilhelm Köeppen, com 
preci pitação média anual de 1.614 mm e incidência média de radiação solar anual de 7,05 h dia-1 (Corrêa et al., 1982). O balanço hídrico da safra de 2000/ 2001 encontra-se na figura 1.

No ano de plantio da variedade RB 72454, em 1997, foram realizadas a correção do solo com cal cário dol omítico, a adubação no sulco de plantio com $400 \mathrm{~kg} \mathrm{ha}^{-1}$ de 04-20-20 e a adubação de cobertura com $160 \mathrm{~kg}$ ha-1 desulfato deamônio. Nos anos seguintes (1998, 1999 e 2000), após as col heitas, fez-seadubação com $350 \mathrm{~kg} \mathrm{ha}^{-1}$ de 20-00-30 durante a real ização do tríplicecultivo (escarificação, adubação e gradagem na mesma operação). As colheitas anterior es ao ensaio eram feitas manual mente com a cana queimada, e, no momento do carregamento, entravam na área um trator e o caminhão transportador da cana col hida. As avaliações foram realizadas na terceira soqueira, que se encontrava num espaçamento de 1,30 m entre as linhas.

Os resultados das análises químicas do solo na profundidade de 0-0,10 m foram: $\mathrm{pH}\left(\mathrm{CaCl}_{2}\right)-4,80$, $\mathrm{H}+\mathrm{Al}-1,84 \mathrm{cmol}_{\mathrm{C}} \mathrm{dm}^{-3}, \mathrm{Al}^{3+}{ }_{-} 0,1 \mathrm{cmol}_{\mathrm{C}} \mathrm{dm}^{-3}$, M.O.$9,2 \mathrm{~g} \mathrm{dm}^{-3}, \mathrm{Ca}^{2+}-0,71 \mathrm{cmol}_{\mathrm{C}} \mathrm{dm}^{-3}, \mathrm{~K}-0,19 \mathrm{cmol}_{\mathrm{C}} \mathrm{dm}^{-3}$, P- 6,6 $\mathrm{mg} \mathrm{dm}^{-3}$. Na profundidade de 0,10 a 0,60 m, os resultados foram: $\mathrm{pH}\left(\mathrm{CaCl}_{2}\right) 5,10, \mathrm{H}+\mathrm{Al}$ $1,91 \mathrm{cmol}_{C} \mathrm{dm}^{-3}, \mathrm{Al}^{3+} \mathrm{O}, 0 \mathrm{cmol}_{\mathrm{C}} \mathrm{dm}^{-3}$, M.O.- $3,3 \mathrm{~g} \mathrm{dm}^{-3}$, $\mathrm{Ca}^{2+}-0,63 \mathrm{cmol}_{\mathrm{c}} \mathrm{dm}^{-3}, \mathrm{~K}-0,11 \mathrm{cmol}_{\mathrm{c}} \mathrm{dm}^{-3}, \mathrm{P}-$ $1,5 \mathrm{mg} \mathrm{dm}^{-3}$.

O delineamento experimental utilizado foi o inteiramente casualizado. O ensai ofoi realizado em faixas, tendo cada tratamento seis linhas de $200 \mathrm{~m}$, sendo as avaliações restritas às linhas centrais, deixando as extremidades como bordaduras. Os tratamentos, aplicados em 02/11/2000, foram: E 1: escarificação a 0,15 m de profundidade, adubação e gradagem; E 2: escarificação a $0,30 \mathrm{~m}$ de profundidade, adubação e gradagem; GR: adubação e gradagem. O equipamento utilizado para esse tríplice cultivo foi o Cultivador Tríplice Operação, da empresa DMB, tracionado por trator Massey Fergunson (110 HP). A escarificação teve o objetivo de descompactar o solo na profundidade determinada para cada tratamento.

Foram, ainda, determinadas as propriedades físicas do solo em uma área onde não houve a interferência deste manejo (tríplice cultivo), denominada "Referência", mas que vinha sendo utilizada da mesma forma dos tratamentos citados anteriormente. Não foram avaliados, nessa última área, o sistema radicular ea produtividade pelo fato de ser um local onde não foi realizada a adubação do solo, já que esta interfere no desenvol vimento da planta. A análise granulométrica do solo na camada de $0-0,25$ m de profundidade mostrou $655 \mathrm{~g} \mathrm{~kg}^{-1}$ de areia, $85 \mathrm{~g} \mathrm{~kg}^{-1}$ de silte e $260 \mathrm{~g} \mathrm{~kg}^{-1}$ de argila.

Foram coletadas, na segunda quinzena de novembro e na primeira de dezembro, amostras indeformadas, usando anel de $5,8 \mathrm{~cm}$ de diâmetro e $4 \mathrm{~cm}$ de altura para as determinações de densidade do solo, porosidade total e distribuição do tamanho de poros, esta última em mesa de tensão (E mbrapa, 1997). As coletas foram efetuadas em quatro repetições, nas profundidades de 0-0,25 e 0,25$0,50 \mathrm{~m}$, a $0,45 \mathrm{~m}$ da touceira. O model o estatístico deanál ise devariância foi o de parcel as subdi vididas, tendo sido o manejo considerado como tratamento principal e as profundidades como tratamento secundário. O teste Tukey $(p<0,05)$ foi usado para comparação de médias. Os dados de porosidade do solo (em percentagem) foram submetidos à transformação arc sen $\sqrt{ }(P / 100)$, em que "P" é a percentagem.

Para avaliação das raízes, em março de 2001, foram abertas quatro trincheiras por tratamento,

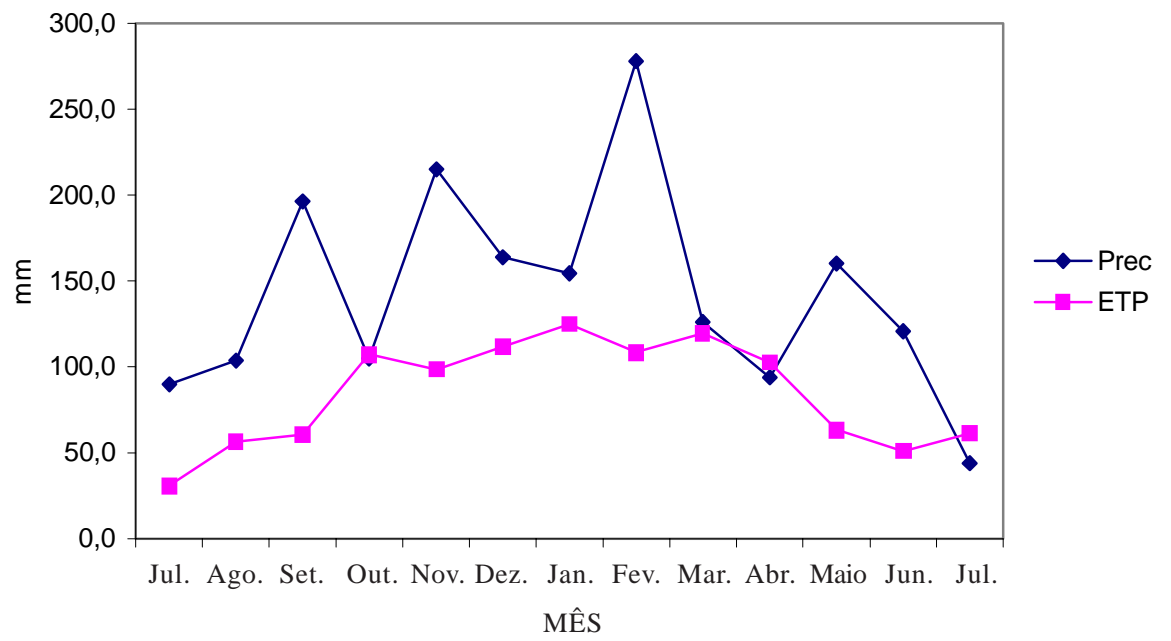

Figura 1. Balanço hídrico normal mensal, referente ao período de julho de 2000 a julho de 2001. 
120 dias após o tríplice cultivo (após o pleno desenvolvimento do novo sistema radicular), transversais à linha de plantio, com $0,75 \mathrm{~m}$ de largura, a partir da touceira, e0,50 m de profundidade, conforme o método da parede do perfil (Böhm, 1979). O perfil foi, então, preparado e as raízes expostas com rolo escarificador. Em seguida, estas foram pintadas individual mente com tinta esmal te branca, para maior facilidade nas avaliações posteriores. Ajustou-se uma tela de mal ha 0,25 x 0,25 m noperfil (Cintra \& Neves, 1996). A partir da touceira, foram feitas três fotos digitais na camada de $0-0,25 \mathrm{~m}$ de profundidade e três na de 0,25-0,50 m, obtendo-se, assim, seis imagens por repetição (trincheira). Estas imagens foram anal isadas pel o programa SI ARCS $\AA^{\text {, }}$ obtendo-se a área e o comprimento de raízes numa área de 0,325 $\mathrm{m}^{2}(0,65 \times 0,50 \mathrm{~m})$, conformeJ orge et al. (1996). Analisou-sea imagem atéà distância de $0,65 \mathrm{~m}$ da touceira pel o fato de a cana estar espaçada a 1,30 mentre as linhas e o método indicar a análise até à metade da entrelinha. O estudo estatístico constou de anál ise de variância complementada pelo teste de comparação de médias (Tukey, $p<0,05$ ).

Para as avaliações referentes à produtividade, realizadas em julho de 2001 , foram feitas sete repetições em cada tratamento, tendo cada parcela $39 \mathrm{~m}^{2}$ (três linhas de $10 \mathrm{~m}$, espaçadas em 1,30 m). Durantea col heita, em julho de 2001, todos os col mos das parcelas foram contados, para determinação do número de colmos por hectare. De cada parcela, foram separados 10 col mos seguidos na linha, para determinações da produtividade e do diâmetro e comprimento médio de colmos. Para a análise estatística, transformaram-se os dados de contagem de colmos por meio da raiz quadrada $\left(\sqrt{ } n h^{-1}\right)$. 0 estudo estatístico destes dados constou do teste de comparação de médias (Tukey, $p<0,05$ ).

\section{RESULTADOS E DISCUSSÃO}

Os val ores de densi dade do sol o variaram de 1,44 (área de referência) a $1,73 \mathrm{~kg} \mathrm{dm}^{-3}$ (tratamento GR) (Quadro 1). As densidades do solo dos três tratamentos foram significativamente maiores do que as da referência.

O sol o com tratamento $\mathrm{E} 1$ apresentou densidade do solo significativamente inferior ao do solo com tratamento E2 ( $1,57 \mathrm{~kg} \mathrm{dm}^{-3}$ para oE 1 e $1,63 \mathrm{~kg} \mathrm{dm}^{-3}$ para oE2). Com isso, observou-se que a escarificação a 0,30 m de profundidade foi menos efetiva do quea escarificação a 0,15 m. Os val ores de densidade do solo dos tratamentos E 1 e E 2 foram intermediários em relação à referência e ao tratamento $G R$, mas não são consi derados val ores el evados para estetipo de solo. Segundo Russell (1988), Barbieri et al. (1997) e Borges et al. (1999), valores altos de densidade do solo prejudicam o desenvol vimento das plantas, pela restrição à penetração de raízes.

A densidade mais el evada do tratamento GR $\left(1,73 \mathrm{~kg} \mathrm{dm}^{-3}\right)$ indica a presença de compactação do solo, justificada pel o tráfego de veículos pesados na área por ocasião da colheita da cana-de-açúcar. Estes resultados estão de acordo com os de Medina (1985), Freitas (1987) e Bastos (1987), que afirmaram ser o intenso tráfego de maquinários um dos principais responsáveis pela compactação dos solos.

A escarificação não apresentou o efeito esperado: a descompactação do solo, com conseqüente aumento da macroporosidade. As macroporosidades dos tratamentos $E 2$ e $E 1$, com médias de 0,082 e $0,081 \mathrm{~m}^{3} \mathrm{~m}^{-3}$, respectivamente, eda Referência, com média de $0,826 \mathrm{~m}^{3} \mathrm{~m}^{-3}$, foram significativamente superiores à do GR, com média de $0,065 \mathrm{~m}^{3} \mathrm{~m}^{-3}$, mas não diferiram entre si.

\section{Quadro 1. Densidade do solo (Ds), macro e microporosidades e porosidade total em Latossolo Vermelho, em ensaio com manejo de pós-colheita de soqueira de cana-de-açúcar}

\begin{tabular}{|c|c|c|c|c|}
\hline Tratamento(1) & Ds & Macroporo & Microporo & Total \\
\hline & $\mathrm{kg} \mathrm{dm}^{-3}$ & 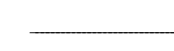 & $\mathrm{m}^{3} \mathrm{~m}^{-3}$ & 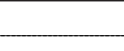 \\
\hline $\begin{array}{l}\text { Referência } \\
\text { E } 1 \\
\text { E2 } \\
\text { GR }\end{array}$ & $\begin{array}{l}1,44 \mathrm{~d}^{(2)} \\
1,57 \mathrm{c} \\
1,63 \mathrm{~b} \\
1,73 \mathrm{a}\end{array}$ & $\begin{array}{l}0,083 \mathrm{a} \\
0,081 \mathrm{a} \\
0,082 \mathrm{a} \\
0,065 \mathrm{~b}\end{array}$ & $\begin{array}{l}0,273 c \\
0,292 b \\
0,280 c \\
0,320 a\end{array}$ & $\begin{array}{l}0,355 a \\
0,370 a \\
0,362 a \\
0,385 a\end{array}$ \\
\hline $\begin{array}{l}0-0,25 \mathrm{~m} \\
0,25-0,50 \mathrm{~m}\end{array}$ & $\begin{array}{l}1,59 \mathrm{~A} \\
1,58 \mathrm{~A}\end{array}$ & $\begin{array}{l}0,078 \mathrm{~A} \\
0,077 \mathrm{~A}\end{array}$ & $\begin{array}{l}0,284 \mathrm{~A} \\
0,300 \mathrm{~A}\end{array}$ & $\begin{array}{l}0,361 \mathrm{~A} \\
0,380 \mathrm{~A}\end{array}$ \\
\hline $\begin{array}{l}\text { C.V. parcela (\%) } \\
\text { C.V. subparcela (\%) }\end{array}$ & $\begin{array}{l}2,35 \\
4,75\end{array}$ & $\begin{array}{l}2,33 \\
2,27\end{array}$ & $\begin{array}{l}2,41 \\
5,75\end{array}$ & $\begin{array}{l}6,67 \\
7,08\end{array}$ \\
\hline
\end{tabular}

(1) Referência: testemunha (área não manejada); E 1: escarificação a 0,15 m de profundidade, adubação e gradagem; E 2: escarificação a 0,30 m de profundidade, adubação e gradagem; GR: adubação e gradagem. Profundidades avaliadas: 0-0,25 e 0,25-0,50 m. Parcelas: tratamento; subparcela: profundidades. (2) Letras minúsculas diferentes, nas colunas, indicam diferença significativa entre os tratamentos e maiúsculas, diferença significativa entre as profundidades (Tukey, $p<0,05$ ). 
Em relação à microporosidade, a GR foi significativamente superior à dos demais tratamentos, com média de $0,320 \mathrm{~m}^{3} \mathrm{~m}^{-3}$. A Referência e o E2 não diferiram entre si, sendo significativamente inferiores ao E 1.

Houve predominância dos microporos em relação aos macroporos, em todos os tratamentos enas duas profundidades (Quadro 1), sendo essa diferença mais acentuada entre o GR e a Referência, confirmando a compactação da área, pois, segundo Borges et al . (1999), a compactação causa um incremento na quantidade de poros menores.

Não houve diferença significativa de porosidade total entre a Referência e os tratamentos, e mesmo entre estes. Os valores variaram de 0,355 a $0,385 \mathrm{~m}^{3} \mathrm{~m}^{-3}$. Para Kiehl (1979), um solo ideal para produção agrícola deve apresentar $0,50 \mathrm{~m}^{3} \mathrm{~m}^{-3}$ de porosidade total, sendo 1/3 macroporos e 2/3 microporos. Para Baver et al. (1972), ovalor mínimo de macroporos deve ser de $0,10 \mathrm{~m}^{3} \mathrm{~m}^{-3}$ para promover o desenvol vimento satisfatório do sistema radicular. Constatou-se que todos os tratamentos apresentaram macroporosidade inferior ao valor mínimo, considerado o ideal por estes autores. Os baixos valores de porosidade total emacroporosidade são conseqüência dos al tos valores de densidade do solo encontrados (Carvalho et al., 1999). Silva \& Ribeiro (1997), estudando o efeito de vários anos de cultivo convencional de cana-de-açúcar, verificaram que, nos solos com maior tempo de cultivo, a porosidade diminuía, com maior evidência para a macroporosidade, visto que esta última representa os espaços entre os agregados mais afetados pel omanejo.

Esses resultados indicam que a escarificação do solo com o tríplice cultivo se faz necessária tanto para reduzir a densi dade do sol o ea microporosidade quanto para aumentar a macroporosidade, uma vez que na área onde esta não foi realizada (GR), estas propriedades apresentaram-se menos adequadas.

Não houve diferença significativa entre os manejos testados (E1, E 2 e GR) para área e comprimento totais de raízes (Quadro 2), divergindo dos resultados encontrados por Duruoha et al. (2001), que verificaram que a compactação do solo reduz o desenvolvimento das raízes de cana-deaçúcar.

As diferenças não-significativas para área e comprimento de raízes são decorrentes, provavelmente, da grande variabilidade entre os ambientes radiculares, elevando a diferença mínima exigida para a significância. Esta variabilidade do solo é devida ao fato deas raízes crescerem ou seramificarem em locais propícios ao seu desenvolvimento, desviando de zonas menos favoráveis, seguindo caminhos de menor resistência em fendas e canais formados pela fauna e matéria orgânica do solo (Atkinson, 1980). Outra explicação para a ausência
Quadro 2. Área e comprimento totais de raízes de soqueira de cana-de-açúcar em uma área de 0,325 $\mathrm{m}^{2}$, em ensaio de manejos de pós-colheita

\begin{tabular}{ccc}
\hline Tratamento(1) & Área & Comprimento \\
\hline & $\mathrm{cm}^{2}$ & $\mathrm{~cm}$ \\
E 1 & $42,78 \mathrm{a}(2)$ & $300,64 \mathrm{a}$ \\
E 2 & $39,03 \mathrm{a}$ & $299,20 \mathrm{a}$ \\
GR & $30,95 \mathrm{a}$ & $221,68 \mathrm{a}$ \\
C.V. (\%) & 38,61 & 31,71
\end{tabular}

(1) E 1: escarificação a 0,15 $\mathrm{m}$ de profundidade, adubação e gradagem; E2: escarificação a 0,30 m de profundidade, adubação e gradagem; GR: adubação e gradagem. ${ }^{(2)}$ Letras diferentes, nas colunas, indicam diferença significativa (Tukey, $p<0,05$ ).

de diferença estatística entre os tratamentos é o fato deas três áreas se apresentarem compactadas ecom baixa fertilidade, isto é, mesmo que o tratamento GR tenha apresentado condições físicas consi deradas mais inadequadas ao desenvolvimento das raízes, estas condições foram limitantes também para os tratamentos E 1 e E2.

Para a área de raízes em diferentes profundi dades e distâncias da touceira, verificou-se que não houve diferença significativa entre os tratamentos (Quadro 3). Quanto ao comprimento de raízes, somentena camada de 0,25 a 0,50 m houve diferença significativa, em que o tratamento E 1 foi superior aos demais, com média de 0,810 m. Também não houve diferença significativa entre os tratamentos, com relação ao comprimento de raízes conforme a distância da touceira. O fato de não ter ocorrido esta diferença na distribuição de raízes entre os tratamentos, exceto para comprimento de raízes na camada de 0,25 a 0,50 m, pode ser conseqüência da boa condição hídrica do solo durante o desenvolvimento da terceira soca (Figura 1 ), indicando que o sistema radicular não teve necessidade de se aprofundar, mesmo que as condições físicas do sol o se diferenciassem. Além do mais, Duruoha et al. (2001), consideram a maior disponibilidade de água como fator de diminuição da resistência à penetração do solo.

I vo (1999), estudando a distribuição do sistema radicular da cana-de-açúcar em solo de Tabuleiro Costeiro sob diferentes preparos, concluiu que a distribuição das raízes no perfil mostra-se diferente entre os preparos, tendo as raízes, no local do preparo convencional raso, concentrado na área do sulco de plantio. Observou, ainda, que opreparo convencional profundo levou ao desenvolvimento mais uniforme das raízes. No presentetrabalho, a escarificaçãomais profunda (E2) não resultou em maior distribuição de raízes em profundidade, ficando estas mais concentradas até $0,25 \mathrm{~m}$ de profundidade. $\mathrm{O}$ mesmo ocorreu com relaçãoà distância da touceira (Quadro 3). 
As produções da soqueira não apresentaram diferença estatística entre os tratamentos (Quadro 4), mesmo que as propriedades físicas do solo tenhamse mostrado distintas. Estes resultados indicam que os manejos testados não al teraram a produtividade, o número de colmos, bem como seus comprimentos e diâmetros médios. Embora não tenha sido registrada diferença estatística no tratamento onde a escarificação foi realizada a 0,30 m (E2), verificouse maior produção em virtude do maior número de colmos, contrastando com os resultados das propriedades físicas do solo, em que o tratamento E1 apresentou-se melhor. A semelhança entre os tratamentos pode ser reflexo da disponibilidade de água (Figura 1), visto que, em nenhum momento, os tratamentos passaram por estresse hídrico. Concluindo, não se observou redução de produção decorrente da compactação do solo, quando o regime hídrico foi adequado para o desenvolvimento da cultura. Segundo Fiorin et al. (1997), a restrição ao crescimento das raízes reduzi u mais a produtividade das culturas em anos em que ocorreu déficit hídrico.
Rosolem et al. (1992), estudando a cultura do trigo, concluíram que o desenvol vimento do sistema radicular é proporcional ao da parte aérea, concordando com o presente trabal ho, no qual tanto as raízes quanto a produtividade de colmos não diferiram entresi.

\section{CONCLUSÕES}

1. O manejo de pós-col heita em soquei ras de canade-açúcar alterou a densidade do solo, a macro e a microporosidade.

2. A escarificação a $0,15 \mathrm{~m}$ de profundidade proporcionou maior comprimento de raízes na camada de 0,25 a 0,50 m.

3. Não se observou redução na área e no comprimento de raízes e na produção de cana-deaçúcar decorrentes do nível de compactação do solo.

Quadro 3. Área e comprimento de raízes de soqueira de cana-de-açúcar em diferentes profundidades e distâncias da touceira, em ensaio de manejo de pós-colheita

\begin{tabular}{|c|c|c|c|c|}
\hline \multirow{2}{*}{ Tratamento(1) } & \multicolumn{2}{|c|}{ Profundidade $(\mathrm{cm})$} & \multicolumn{2}{|c|}{ Distância (cm) } \\
\hline & $0-25$ & $25-50$ & $0-32,5$ & $32,5-65,0$ \\
\hline & \multicolumn{4}{|c|}{ Área de raízes, $\mathrm{cm}^{2}$} \\
\hline $\begin{array}{l}\text { E } 1 \\
\text { E2 } \\
\text { GR }\end{array}$ & $\begin{array}{l}31,42 a^{(2)} \\
31,04 a \\
23,40 a\end{array}$ & $\begin{array}{r}11,37 \text { a } \\
7,99 \text { a } \\
7,55 \text { a }\end{array}$ & $\begin{array}{l}23,79 \mathrm{a}^{(1)} \\
24,76 \mathrm{a} \\
17,70 \mathrm{a}\end{array}$ & $\begin{array}{l}19,00 \mathrm{a} \\
14,29 \mathrm{a} \\
13,25 \mathrm{a}\end{array}$ \\
\hline \multirow[t]{2}{*}{ C.V. (\%) } & 45,28 & 25,10 & 43,37 & 37,60 \\
\hline & \multicolumn{4}{|c|}{ Comprimento de raízes, cm } \\
\hline $\begin{array}{l}\text { E } 1 \\
\text { E2 } \\
\text { GR }\end{array}$ & $\begin{array}{l}219,69 a^{(1)} \\
245,56 a \\
170,14 a\end{array}$ & $\begin{array}{l}80,95 a \\
53,64 b \\
5155 b\end{array}$ & $\begin{array}{l}160,92 a^{(1)} \\
192,12 a \\
133,77 a\end{array}$ & $\begin{array}{r}13972 \text { a } \\
107,08 \text { a } \\
87,90 a\end{array}$ \\
\hline C.V. (\%) & 40,12 & 18,60 & 34,12 & 38,87 \\
\hline
\end{tabular}

(1) E1: escarificação a 0,15 m de profundidade, adubação e gradagem; E2: escarificação a 0,30 m de profundidade, adubação e gradagem; GR: adubação e gradagem. ${ }^{(2)}$ Letras diferentes, nas colunas, indicam diferença significativa $($ Tukey, $p<0,05)$.

Quadro 4. Produtividade, número de colmos, comprimento e diâmetro médios de colmos de cana-deaçúcar, em ensaio de manejo pós-colheita

\begin{tabular}{|c|c|c|c|c|}
\hline \multirow{2}{*}{ Tratamento(1) } & \multirow{2}{*}{ Produtividade } & \multicolumn{3}{|c|}{ Colmo } \\
\hline & & Número & Comprimento & Diâmetro \\
\hline & t ha-1 & $\sqrt{ }$ h ha-1 & $\mathrm{m}$ & $\mathrm{cm}$ \\
\hline $\begin{array}{l}\text { E1 } \\
\text { E2 } \\
\text { GR }\end{array}$ & $\begin{array}{l}78,34 \mathrm{a}^{(2)} \\
98,72 \mathrm{a} \\
90,93 \mathrm{a}\end{array}$ & $\begin{array}{l}284,26 a \\
309,33 a \\
293,62 a\end{array}$ & $\begin{array}{l}1,81 \text { a } \\
2,03 \text { a } \\
2,02 \text { a }\end{array}$ & $\begin{array}{l}2,22 a \\
2,35 a \\
2,46 a\end{array}$ \\
\hline C.V. (\%) & 27,60 & 24,31 & 8,75 & 7,77 \\
\hline
\end{tabular}

(1) E1: escarificação a 0,15 m de profundidade, adubação e gradagem; E2: escarificação a 0,30 m de profundidade, adubação e gradagem; GR: adubação e gradagem. ${ }^{(2)}$ Letras diferentes, nas colunas, indicam diferença significativa (Tukey, $\left.p<0,05\right)$. 


\section{LITE RATURA CITADA}

ALBUQUERQUE, J.A. \& REINERT, D.J. Densidade radicular do milho considerando os atributos de um solo com horizonte B textural. R. Bras. Ci. Solo, 25:539-549, 2001.

ATKINSON, D. The distribution and effectiveness of the root of tree crops. Hortic. Rev., 2:424-490, 1980.

BARBIERI, J.L.; ALLEONI, L.R.F. \& DONZELLI, J.L. Avaliação agronômica e econômica de sistemas de preparo de sol o para cana-de-açúcar. R. Bras. Ci. Solo, 1:89-98, 1997.

BASTOS, S.A. Cana-de-açúcar, o verde mar de energia. São Paulo, Ícone, 1987. 127p.

BAVER, L. D.; GARDNER, W. H. \& GARDNER, W.R. Soil physics. 4.ed. New York, J ohn Wiley \& Sons, 1972. 529p.

BÖHM, W. Methods of studing root systems. New York, SpringVerlag, 1979. 185p.

BORGES, E.N.; LOMBARDI NETO, F.; CORREAA, G.F. \& BORGES, E.V.S. Alterações físicas introduzidas por diferentes níveis de compactação em Latossolo VermelhoEscuro textura média. Pesq. Agropec. Bras., 34:1663-1667, 1999.

CARVALHO, E.J.M.; FIGUEIREDO, M.S. \& COSTA, L.M. Comportamento físico-hídrico de um Podzólico VermelhoAmarelo câmbico fase terraço sob diferentes sistemas de manejo. Pesq. Agropec. Bras., 34:257-265, 1999.

CINTRA, L.F.D. \& NEVES, C.S.V.J . Aspectos metodológicos do estudo do sistema radicular de plantas perenes através de imagens. B. Soc. Bras. Ci. Solo, 21:91-94, 1996.

CORRÊA, A.R.; GODOY, H. \& BERNARDES, R.L.M. Características climáticas de Londrina. 2.ed. IAPAR, Londrina, 1982, 16p. (Circular, 5)

CORSINI, P.C. Problemas causados pela compactação dos sol os. STAB, 18:8-12, 1993.

CORSINI, P.C. \& FERRAUDO, A.S. Efeitos de sistemas de cultivo na densidade e na macroporosidade do solo e no desenvolvimento radicular do milho em Latossolo Roxo. Pesq. Agropec. Bras., 34:289-298, 1999.

DURUOHA, C.; BENEZ, S.H. \& CRUSCIOL, C.A.C. Desenvolvimento do sistema radicular da cana-de-açúcar (Saccharum spp.) em função da compactação, do tipo de solo e do teor de água. Energia Agric., 16:35-46, 2001.

EMPRESA BRASILEIRA DE PESQUISA AGROPECUÁRIA EMBRAPA. Manual de métodos de análise de solo. 2.ed. Rio de J aneiro, 1997. 212p.

FIORIN, J.E.; REINERT, D.J \& \& ALBUQUERQUE, J.A. Armazenamento deágua no sol o e produtividade da cultura de milho em um Podzólico Vermel ho-Amarelo. R. Bras. Ci. Solo, 21:249-255, 1997
FREITAS, G.R. Preparo do solo. In: PARANHOS, S.B., coord. Cana-de-açúcar - cultivo e utilização. Campinas, Fundação Cargill, 1987. p.271-283.

HUMBERT, R.P. El cultivo de la caña de azucar. México, Companhia Editorial Continental, 1974. 719p.

IVO, W.M. Distribuição do sistema radicular da cana-de-açúcar em solo de tabuleiro costeiro. In: WORKSHOP SOBRE SISTEMA RADICULAR: METODOLOGIAS E ESTUDO DE CASOS, Aracaju, 1999. Anais. Aracaju, Embrapa Tabuleiros Costeiros, 1999. p.101-114.

J ORGE, L.A.C.; RALISCH, R.; ABI SAAB, O.J .G.; MEDINA, C.C.; GUIMARÃES, M.F.; NEVES, C.S.V.J .; CRESTANA, S.; CINTRA, F.L.D.; BASSOI, L.H. \& FERNANDES, S.B.V. Aquisição de imagens de raízes. In: J ORGE, L.A.C., ed. Recomendações práticas para aquisição de imagens digitais analisadas através do SIARCS. São Carlos, Embrapa Instrumentação Agropecuária, 1996. CD-ROM.

KIEHL, E.J. Manual de edafologia: relação solo-planta. São Paulo, Ceres, 1979. 262p.

LIBARDI, P.L. \& LIER, Q.J.V. Atuação dos fatores físicos do solo no desenvolvimento do sistema radicular. In: WORKSHOP SOBRE SISTEMA RADICULAR: MEDOLOGIAS E ESTUDO DE CASOS. Aracaju, 1999. Anais. Aracaju, Embrapa - Tabuleiros Costeiros, 1999. p.47-56.

MEDINA, B.F. Influência de dois métodos de preparo de área na compactação de um Latossol o Amarelo. R. Bras. Ci. Solo, 9:67-71, 1985.

ORLANDO FILHO, J .; BITTENCOURT, V. C. \& ALVES, M. C. Aplicação de vinhaça em solo arenoso do Brasil e poluição do lençol freático com nitrogênio. STAB, 13:14-16, 1995.

ROSOLEM, C.A.; FURLANI J ÚNIOR, E.; BICUDO, S.J .; MOURA, E.G. \& BULHÕES, L.H. Preparo do solo e sistema radicular do trigo. R. Bras. Ci. Solo, 16:115-120, 1992.

RUSSELL, E.W. Soil conditions and plant growth. 11.ed. New York, Alan Wild, 1988. 991p.

SECRETARIA DA AGRICULTURA E DO ABASTECIMENTO. PARANÁ RURAL - SEAB/PR. Programa de Desenvolvimento Rural do Paraná. Manual técnico do subprograma de manejo e conservação do solo. Curitiba, 1994. $372 p$.

SILVA, A.J .N. \& RIBEIRO, M.R. Caracterização de um Latossolo Vermel ho-Amarel o sob cultivo contínuo de cana-de-açúcar no estado de Alagoas: atributos morfológicos e físicos. R. Bras. Ci. Solo, 21:677-684, 1997.

VERMA, R.S. Ratoon decline in sugar cane. Cooperative Sugar, 26:349-351, 1995. 
A.F. PAULINO et al. 